\title{
Japan turns pro-life: recent change in reproductive health policy and challenges by new technologies
}

\author{
Etsuji Okamoto*
}

Abstract

Japan, known as a pro-choice country in terms of abortion, is currently facing the increase of "selective abortions" thanks to new prenatal screening. Efforts to restrict proliferation of new technology has not been successful and it is likely that Japan will turn pro-life by strictly enforcing the Maternity Protection Act (MPA), which prohibits abortions due to "fetal cause".

Keywords: Abortions, Prenatal Screening, Pro-Life, Pro-Choice, Genetic Counseling

Copyright: (C) 2014 by Kerman University of Medical Sciences

Citation: Okamoto E. Japan turns pro-life: recent change in reproductive health policy and challenges by new technologies. Int J Health Policy Manag 2014; 2: 61-63. doi: 10.15171/ijhpm.2014.15
Article History:

Received: 14 January 2014

Accepted: 5 February 2014

ePublished: 10 February 2014

Correspondence to:

Etsuji Okamoto

Email: atoz@niph.go.jp

\section{Introduction}

Japan is known as a pro-choice country in terms of abortions. However, the policy is increasingly brought under debate in relation to the recent proliferation of new medical technology such as Assisted Reproductive Technology (ART), NonInvasive Prenatal Testing (NIPT) because selective abortions, if left controlled, may conflict with the national population policy to encourage child bearing.

In this article, the author describes the background and recent development surrounding the new technology from the viewpoint of the reproductive health policy.

\section{1) History of Japan's policy on abortions}

Japan has seen a surge in birth rate in the post-war period (1946-9). Birth rate in 1947 was 34.3 per thousand population far higher than the pre-war period (29.2 in 1940). Such a sharp rise in birth rate alerted the government, which was struggling to sustain the nation's life under the shortage of food and resources at that time. The government, alerted at the uncontrollable population growth, encouraged birth control and simultaneously resorted to abortions for the purpose of population control.

In 1948, the Eugenics Protection Act (EPA) was enacted. The act was originally enacted as the National Eugenics Act in 1940, which authorized compulsory sterilization on people with genetic diseases. The purpose of the EPA was "preventing the births of offspring of inferior quality as well as protecting the health and well-being of maternity (section 1 )".

The new EPA expanded the scope of compulsory sterilization to include people with psychiatric diseases, mental retardation as well as leprosy. A total of 16,319 compulsory sterilizations were performed between 1949 and 1996. Only when EPA was revised in 1996, such practice was abolished. Voluntary sterilizations are continuing and a total of 3,498 sterilizations were performed in 2012, of whom 3,471 were women (1).

The EPA also authorized abortions for the same reasons with compulsory sterilization (when mothers or spouses have genetic disease, mental retardation, psychiatric diseases, leprosy as well as pregnancies due to rape). This was a remarkable departure from Japan's restrictive policy on abortions in the pre-war period. Japan's penal code, which was enacted in 1902, penalized abortions as crimes and remains effective today. Abortions were legalized for the first time by the EPA in 1948 as a special law superseding the penal code.

In 1952, the EPA was revised again to expand the conditions of abortions to include the so-called "economic cause", authorizing abortions when "continuation of pregnancies jeopardize the health of mothers either physically or economically" (2). The "economic cause" was interpreted liberally and increased the number of abortions dramatically from 196,883 in 1949 to the peak of $1,170,134$ in 1955 . In the peak year of 1957, nearly $40 \%$ of pregnancies were aborted. The number of live births declined considerably, effectively putting an end to the post-war baby boom. The population control in the post-war Japan was achieved through abortions, not through birth control (Figure 1). Figure 1 shows a sharp drop in live births in 1966. This was due to a superstition of "firing horse year" in oriental calendar which rotates every 60 years. People voluntarily withheld child births believing in a superstition that girls born in this year will not make happy marriage. What is noteworthy from demographical viewpoint was that the number of abortions remained the same with adjacent years. In this particular year, population control was achieved predominantly through birth control, not abortions.

2) Change in population policy and revision of the EPA in 1996

The post-war baby boom was successfully controlled. The second baby boom occurred in early 1970s. Since then, fertility rate has constantly declined. In early 1990s, the Total Fertility Rate (TFR) fell below 1.5 live births per woman in her life time during reproductive age (15-49), forcing the government to 


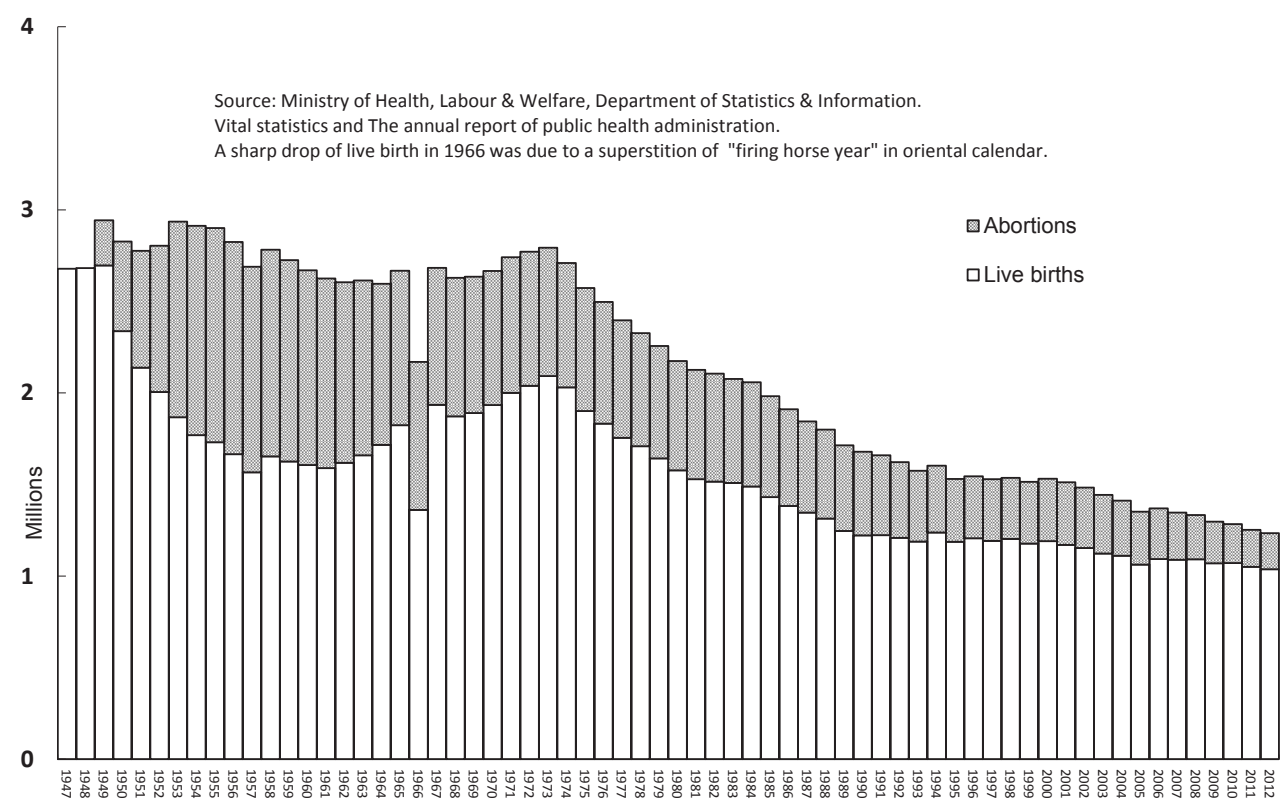

Figure 1. Trend of the number of abortions and live births in Japan

reconsider its birth control policy and switch to a new policy to increase birth rate. The policy measure was dubbed "Angel Plan" and was adopted in December 1994. The Angel Plan did not officially include any measures about abortions.

The EPA was revised in 1996 and was renamed to "The Maternity Protection Act (MPA)". The compulsory sterilization was abolished altogether and the purpose of the law was revised to "protection of life and health of mothers" renouncing the eugenic purpose. The MPA authorizes abortions only for two reasons: the economic cause and pregnancies by rape. Abnormalities of fetus (so-called "fetal cause") have never been a valid reason for abortions either under EPA or MPA.

However the "economic cause" has been interpreted liberally and it is easy to have abortions. Currently $99 \%$ of abortions are performed for the "economic cause". Although the number has been declining, a total of 196,639 abortions were performed in 2012 according to the administrative reporting to the government from performing obstericians doctors (1). It is possible for a mother to choose an abortion after she learned of abnormalities of fetuses. Japan's long-standing pro-choice policy provides ways for "eugenics by selective abortions" (3).

\section{3) Challenges of new medical technologies}

Just when Japan faced the problem of declining birth rate and the MPA was revised, new medical technologies started to proliferate. They are ART for infertility and prenatal screening such as triple marker testing on maternal serum. Emergence of these new medical technologies challenged, and complicated, Japan's reproductive health policy.

Reflecting the "ageing" of mothers (average age of mothers rose by 4.2 years from 27.3 in 1973 to 31.6 in 2012 according to vital statistics), ART quickly came into great demand. In-vitro Fertilization (IVF) started in 1983, Frozen Embryo Replacement (FER) in 1988 and Intra-Cytoplasmic Sperm Injection (ICSI) in 1993 (4). In 2008, of the 190,613 treatment cycles, $17.1 \%$ resulted in clinical pregnancies and $10.7 \%$ resulted in live birth deliveries. A total of 21,704 babies were born with ART, or $2.2 \%$ of the total live births (5).
On the other hand, new technologies for prenatal screening also came into common use. When triple marker testing became available shortly after the revision of the MPA, the Ministry of Health, Labour \& Welfare (MHLW) issued a warning to medical community as well as local governments in July 1999 (6). The warning states "there are concerns that the new technology (triple marker testing) may lead to abortion of fetuses with disability and eventually lead to denial of the living rights and lives of people with disabilities. The idea of normalization, in which people with disability can live comfortably with healthy people, is an internationally agreed idea. This is the reason why the EPA was revised to eliminate sterilizations or abortions for the purpose of eugenics. Therefore, doctors should not recommend patients to receive tests, nor required to provide relevant information".

This is a sharp contrast to the U.S., where "obstetricians have an ethical duty to properly inform patients of their options, specifically the availability of screening and diagnostic testing" (7). "As newer, more accurate screening tests emerge, physicians may need to quickly get up to speed on the most recent data and start informing their patients of the existence of these tests. Failure to inform patients of the availability of these more accurate screening tests might result in a wrongful birth or wrongful miscarriage lawsuit if the patient can demonstrate that she would have chosen the newer test, if she had known about it, to avoid the unfortunate outcome that resulted from receiving a conventional screening test or invasive procedure".

\section{4) Controversy over the latest technology}

As predicted, a newer and more accurate screening test emerged in 2011. The new technology, NIPT (8), provided by an American company with a brand name of MaterniT21, stirred a renewed debate.

Obstetricians were concerned with the increase of abortions prompted by NIPT and with good reason. A survey on obstetricians revealed that the number of abortions prompted by prenatal screening had increased by six-fold between 1985-9 and 2005-9 (9). Since NIPT is more accurate than the 
older triple marker testing, it would proliferate quickly if left unchecked.

MHLW and Japan Society of Obstetrics \& Gynecology (JSOG) responded by defining the new technology as "research" and limited providers to participating institutions which have enough number of professional genetic counselors. Consequently, only pregnant mothers who fulfill the research criteria (age: 35 years or older) were given an opportunity of receiving the test.

The role of genetic counselors is to provide objective information for pregnant women to make an informed choice. The fact that Japan's MPA does not authorize abortions because the abnormalities of fetuses (fetal cause) is, of course, an important and indispensable information. However, the counseling was not so promising. According to the NIPT consortium which compiled the records from participating institutions during the six months period from the start in April to September 2013, 53 out of 54 pregnant mothers with confirmed positive results chose abortions (10).

Discussion and policy implications

Japan, once known as one of the most liberal countries in terms of abortions, is increasingly turning to pro-life in the wake of declining population and a need to encourage child births. However, it proved to be a difficult to task to restrict abortions under the present legal system. Japan's abortion legislations (MPA and EPA) have never authorized abortions due to abnormalities of fetuses. The law was enacted when prenatal screening was not available and abortions were performed indiscriminately using the "economic cause".

The lack of "fetal cause" brought about a difficult situation when new prenatal screening became available. Prenatal screening made it possible to selectively abort fetuses using "economic cause". The government and medical community have made efforts to stall the proliferation of the new technology. First, the government ordered doctors not to recommend maternal serum testing in 1999. However, the selective abortions did indeed increased because the government order was not legally binding and it was impossible to prohibit patients from seeking testing and abortions.

When the newer technology emerged, the government and medical community responded by restricting the institutions authorized to provide tests. By restricting institutions to those with enough professional genetic counselors, it was hoped that selective abortions may be avoided. However, the initial results showed that most of pregnant women with confirmed positive results chose abortions despite intense professional counseling. What will happen next? If the less coercive measures such as counseling are ineffective, then more coercive measures involving legal measures may become necessary. It is important to note that Japan's penal code has consistently been pro-life: abortions are punishable with up to one year imprisonment (Penal Code, Sec 212). The criminal penalty has rarely been enforced because the MPA supersedes the Penal Code. It has been possible because of the liberal interpretation of the "economic cause".

If Japan is to strictly enforce the pro-life policy, there will be a good chance that the long-held pro-choice policy based on the liberal interpretation of the legal system may be reconsidered. Japan's population decline is so serious to warrant such a radical policy change realistic.

\section{Ethical issues}

Not applicable.

\section{Competing interests}

The author declares that he has no competing interests.

Author's contribution

EO is the single author of the manuscript.

\section{References}

1. Ministry of Health, Labour \& Welfare (MHLW), Department of Statistics \& Information. Annual report of public health administration, 1949-2012.

2. Wikipedia [homepage on the Internet]. Eugenics in Japan; [about 2 screens]. Available from: http://en.wikipedia.org/wiki/Eugenics_in_ Japan\#Race_Eugenic_Protection_Law

3. Will GF. Eugenics by abortion. Washington Post [serial on the Internet]. 2005 April 14. Available from: [http://www.washingtonpost. com/wp-dyn/articles/A51671-2005Apr13.html]

4. Saito $H$. [Current status of assisted reproductive treatment (ART) in Japan]. Current Information of Maternal \& Child Health 2012; 66: 13-7.

5. Japan Society of Obstetrics \& Gynecology. ART Registry of Japan, 2008 [internet]. Available from: http://plaza.umin.ac.jp/ jsog-art/ ART\%20Registry\%20of\%20Japan,2008.pdf

6. Chief of the Bureau of Children \& Families, Ministry of Health, Labour \& Welfare (MHLW). Warning on maternal serum screening. Administrative directive No. 582, issued on July 21st, 1999 [in Japanese].

7. Wikipedia [homepage on the Internet]. Prenatal diagnosis; [about 4 screens]. Available from: http://en.wikipedia.org/wiki/Prenatal_ diagnosis

8. Sequenom Inc. MaterniT21 [internet]. Available from: http:// laboratories.sequenom.com/maternit21plus/maternit21-plusknowing-about-your-pregnancy

9. Hirahara F. Prenatal screening and importance of genetic counseling. Kanagawa [serial on the Internet]. 2013 October 28. Available from: http://news.kanaloco.jp/localnews/ article/1310280009/

10. More than $90 \%$ chose abortions. Asahi [serial on the Internet]. 2013 November 22. Available from: http://www.asahi.com/articles/ TKY201311220411.html 